\title{
Students and the World Wide Web
}

\section{Issues of Confidence and Competence}

\author{
Jinx Stapleton Watson, Ph.D. \\ <Jinx-Watson@utk.edu> \\ Assistant Professor \\ School of Information Sciences, University of Tennessee \\ United States of America
}

\begin{abstract}
As students ponder their use of the new technologies in schools and at home, what issues are raised for librarians and teachers? Do teens exaggerate their confidence and competence as they report their perceptions of using technology? In this study, four 16 year olds discussed their personal experiences in using the Internet for work and for pleasure. From their musings, we may begin to see a pattern of developmentally specific activities for using the new technologies that differs from adult expectations.
\end{abstract}

\section{Introduction}

In a previous study (Watson, 1998), I examined the perceptions of a small group of eighth grade students regarding their experience with technology. The students offered insights into personal attributes that included expressing self-confidence as they negotiated their way through the World Wide Web. They articulated particular skills in reading and managing information needed for electronic searches. The overall tone of the students' interviews revealed a sense of familiarity, openness, and independence regarding their use of the Internet, especially the World Wide Web. In the first interview, the students had been involved in a public school system's special technology program for three years. However, in that study, few of the students suggested ways to assess information nor evaluated the quality of search results. Therefore, I wondered whether these particular teens' tone of assurance and sense of confidence matched their specific skills and competence in using the Web. In adolescence, students may project a sense of assurance to mask insecurity or mimic adult behaviors, without sustaining the emotional maturity which adults should exhibit (Erikson, 1950, 1993; Meeks, 1986). Therefore, I wanted to interview the same students two and a half years later to see if their perceptions reflected a similar tone of confidence and competence. I also wanted to hear from the same students because of their unique circumstances, the benefit of their early years in the "twenty-first century" classrooms provided by state funding (Tennessee Code Annotated 493-351). That is, I wondered whether a tone of bravado might emerge because of their developmental age or whether these students genuinely expressed confidence because of their particular competencies from sustained use. I was eager to discover any new issues that these particular students would 
raise. I embarked upon locating as many as possible of the original nine students whose comments I had analyzed for the previous study.

\section{Research Questions}

My umbrella question overlay all subsequent queries and probes: "How do you use the new electronic technologies?" I sought examples of ordinary and special use of technology, specifically of the Internet, to assess how these young people used the World Wide Web as a resource and how they used e-mail, chat rooms and other communication opportunities. I wanted to understand what I had previously perceived as the teens' overt projection of confidence and what skills and competence levels they revealed as they spoke of using technology. I asked how they learned to search for and access information. I listened for instances in which the young people analyzed the quality of information. I probed for examples of critical thinking and evaluation in searching. I remained open to hearing ways of using the Internet that might be particularly youthful endeavors, reflective of teens' developmental needs.

\section{Methodology}

Taking my lead from Dervin's (1977) charge to begin understanding more "about how people make use of libraries, or, for that matter, how they make use of the prime collateral of libraries -information" (p. 17), I continue to seek understanding of young people's perceptions of their use of the new technologies. Since perceptions are not easily measurable, I strive to make sense of others' sense-making (Dervin, 1986) by interpreting incidents and experiences. "The interpretive task begins with perception when a person first encounters new information" (Kuhlthau, 1993, p. 342) and ends with noting patterns, making inferences and going beyond the information given (Bruner, 1973). I wanted to explore each student's experiences, to go beyond them by listening to specific examples, connections and tone, and to probe to make some meaning. As a qualitative interview study, I dedicated myself to listening to what students revealed to me rather than imposing an hypothesis.

I asked how each student used the technologies on his or her own initiative and for school research assignments. Although my interviews followed an open-ended, conversational approach, I prompted each of the interviewees in similar ways by asking for examples. I asked how they assessed sites and books as credible sources of information.

I read each transcribed interview to shed light on a single student's experience. I immersed myself in the text to examine the key phenomena offered to explicate my question, "How do you use the new electronic technologies?" Pollio, Henley \& Thompson (1997) in writing that "the objects of our awareness reveal what is noteworthy for us" (p. 8), suggest that what students choose to share, to tell about their life experiences with technologies will be, indeed, what is important to each as a user. In closely reading a single text, I began to hear what phenomenologists (Gadamer, 1975; Pollio, et. al., 1997) call "a stance." Students appeared to be in the process of creating a singular relationship with the computer, specifically, the Internet, and its capabilities. Each interview text revealed a distinctive stance of use, comfort level, trust, and understanding between individual user and the Internet. I plan to analyze a single student's characteristics and changes in a future study. 
I reviewed all the interview texts as a whole in order to discern patterns amongst the users. In reading widely across all four texts. I noted similarities in the students stories. For example, I found that their stories shared a common stance regarding personal use as different from school use. I noted that each of the students seemed relaxed and proficient in personally using the Internet, but wary of accessing websites for school research purposes. These commonalities offer teachers and librarians a challenge: can we find ways of using students fondness for personal communication as an enticement for school research use? In appreciating what some students say about their use of technology, and in knowing about adolescent developmental needs, we begin to gain understanding about their sense of the current electronic technologies.

\section{Students}

For the current study, each student--formerly eighth graders - was preparing to enter their junior (i.e., penultimate) year of high school. Of the nine students who participated in the original study, I was able to interview three: Polly, J.R., and Mike (aliases from the earlier study). Two students had moved. Although I contacted four others, one declined (Lauralee) saying she was unable to participate. Two (Will and Vel) were unreachable. Will's grandmother said, "In the summer, he hits the streets." Vel's grandmother arranged a time, but was unable to keep him in the house for the time she had set. Another student, Bryce, spent the summer out of town.

To supplement the three student voices, I added comments from another sixteen year old (Tara). As an eighth grader, two and a half years ago, she participated in the phone interview regarding the question, "How do you find information for a research report?" (Watson, unpublished). For purposes of the current study, she interviewed by email. In reading the interviews of Polly, J.R., Mike, and Tara, I note some common themes of use.

\section{Limitations of study}

In making meaning of student perceptions, it is necessary to be cautious in generalizing or drawing conclusions. Nevertheless, discussions with teens can offer insights to those who care to motivate and extend students' learning. Listening to student voices may provide a tip or two; a small but successful idea from young people may lead adults to consider employing it with others. Perceptions also may not constitute reality or truth. Even so, "Understanding the meaning of some experience requires us to describe the intentional stance (or situated perspective) of the event from the point of view of the experiencing person" (Pollio, et al., 1997, p. 8).

I analyzed three reasons why I might not have gained the interest of the students who did not participate in the second study. First, I realized that the previous study tapped a captive audience during school hours. Students may relish an opportunity to get out of class; to be interviewed appears as a novelty. Summertime interviews for young people may not appear as an attractive competitor for leisure time. Second, three of the four who did not participate had no access to home computers. In my earlier study (Watson, 1998), I wondered whether the notion of access offered a stimulant for self-confidence. I suggested that, 
Knowing that one has access and knowing how to access technology may suggest a kind of powerful knowing. In an emergent culture such as one which unfolds before us technologically, learners must feel assured that they can have access, belong to and stay close to the changing culture, rather than fearing its new iterations (p. 1027).

My sense is that, for the students declining to be interviewed-who have no access to the Internet in their own homes, and who have less access to technology in the high school than in their middle school program - a lack of confidence overpowered their sense of the interview as novelty. During their eighth grade years, both Vel and Will regularly used the public library to access Web sites. As sixteen year olds with new interests in work and leisure, being seen at the public library might not as easily fit in with their new roles and images. And third, the "Hawthorne effect" of the state's technology program might offer some insight into the documented enthusiasm and confidence of the eighth grade students in contrast to their current lack of interest in being interviewed. Three students interviewed (J.R., Mike and Tara) had Internet access in their homes. Polly used school and public library access.

\section{Discussion}

To examine notions of confidence and competence in using the Internet, I noted the difference in the tone of talk regarding personal use as opposed to accessing information for school use. The students' words provide two entry points for looking at personal use: "E-mail was a gift from the gods" (Tara) and "I feel . . . confident, just mainly through experience" (Mike).

To examine the broad category of school use, student statements reveal the suspicion and reticence with which some regard searching the World Wide Web for information. 1 use Jason's statement as a header -- "[Web authors] are citing their (sic) selves pretty much" -- to examine the students' hesitation to use the Web for school research. Polly offers the header for discussing technology training, "I don't remember any classes about using the Web."

\section{Personal use: "E-mail was a gift from the gods" (Tara)}

Most teachers and librarians would agree with scholars who suggest that the adolescent period is marked by teens' reaching out and forming strong links to their peers as "an important source of information and opportunity for socialization" (Lefrancois, 1999, p. 348). The four students perceived the Internet mail services as first priority. Each enthusiastically shared their experience and perceptions of communicating with friends and with strangers who share similar hobbies and interests. Tara and Polly, the two females, correspond with friends far and wide, out of state and away at college. Tara wants very much to "keep in touch. . .with a lot of friends who live out of state," so, besides her e-mail account, she downloads instant messenger services to "see which friends are online and to chat with them." She says the difference between this format and chat rooms is you don't talk with "a bunch of random people. . .making it a lot safer, in addition to a lot more interesting."

Polly uses email to "talk to some of my friends in college" and her Chilean exchange student friend "e-mails her family and friends and stuff from school." 
Jason and his girlfriend use WebTV to chat. "We just talk about sports and stuff. . we just set up a time when we can both be on. It's not that much different than using a phone." He also emails "a couple of girls and a couple of guys. We correspond about sports and tips."

It should come as no surprise that teens embrace the Internet as a tool for communicating with their friends and acquaintances. Internet mail services allow teens to keep in touch with many friends, "always" (Tara). To maintain communication effectiveness, teens have learned the latest technologies such as "instant messenger services." Communicating, in all its iterations, fits the developmental need for socialization at this age.

Employing electronic mail services as a more formal source of information, Mike assesses his experience with chat rooms:

bad situations don't arise in a chat room unless you are ignorant to them. . a lot of chat rooms are designed for one hobby or sport and you can go in those and meet people from all over the world in different countries. . . I'm a soccer player and I'm a knife collector, as a hobby, and I'm an avid outdoorsman. And so, for each of those three, there's a different chat room set up explicitly for that. . . . in the knife one, I find myself giving a lot of information. In the hunting one, I've always been an avid outdoorsman, but as far as a hunter I'm very new, and so in that one, I receive a lot more information. . . I talk to people who are at University of Florida, ... UCLA, Indiana, North Carolina, Virginia, the big soccer schools. And I get feedback from them about how they got there, what they like and don't like about their soccer program.

We interpret that Mike perceives himself as knowledgeable of chat rooms. He has considered the reputation of chat rooms, suggesting that one must negotiate them. He uses the chat rooms for focus areas, negotiating familiar terrain. Mike perceives specialty chat rooms as a reference source for his information needs. Selected chat rooms offer him the opportunity to share his expertise and to develop his interests, by offering and seeking information.

Mike manifests two adolescent attributes, that of metacognition, showing one's thinking about thinking or knowing about knowing, and traditional adolescent egocentrism (Vartanian and Powlishta, 1996). As we consider the information processing approach of intelligence, we are reminded that individuals both create a knowledge base and develop cognitive strategies, thus "gradually developing an awareness of self as a knower" (Lefrancois, p. 257). By discussing his interaction with chat rooms and by expressing his opinions in acknowledging both expertise and novice levels of knowledge, Mike illustrates that he thinks about his own thinking (metacognition). Yet, his self-assured and lengthy speech-like responses to the question of "How do you use the technologies," reflect an "adolescent egocentrism" whereby teens perceive that everyone is watching them because they are a special model or example. Pride in knowing how to use the electronic technologies offers a perfect medium for such egocentrism. Many adults lack Mike's experience and self-assurance about using the Internet. The interview experience, also, adds to the perception that he is being singled out for his specialness. Jason, too, portrays himself as confident, "I give . . .(my brothers) tips. . I'm sixteen and my brothers are 20 and 14 ... and over the years, I just pretty much taught myself."

Papert (1993) has called the computer the "children's machine," because today's young people and the computer technologies have grown up together. Young people may express selfconfidence when adults ask them to discuss what they know about technology. Students may 
believe that the questioner or interviewer does not really know about the technologies, per se, rather than appreciating that she is inquiring about the individual's own perceptions as a key to understanding more about use.

\section{Personal use: "I feel . . confident just mainly through experience." (Mike).}

Tara, Jason, and Mike expressed ease and authority in their discussion of personal use. Polly's use was more limited because of lack of convenience, requiring school and public library access to the Web. For her, the "nice thing is the maps. Well, I look at information for colleges." Tara and Jason access music and information about their favorite groups via the Web. Jason reported, "I . . . search what I'm looking for and just type in the words and it will take me right to whatever I want . . . I'm pretty successful, not usually frustrated." Tara "checks up on mostly humorous" Websites. And she "rarely surfs aimlessly. That's just pointless." Thus, we begin to appreciate these students' focused searches for specific topics of personal interest. One can appreciate that these users become more expert because of their regular access and assessment of sites in which they are knowledgeable. The students display a level of critical thinking in their comments about use. Their decisions to accept or reject sites and to know why they do so, show an understanding of how the Web works.

If we begin to understand the characteristics of adolescent behavior, then we appreciate that the confidence exhibited by the adolescents, both at ages thirteen and sixteen, may arise from two sources: one, the natural developmental stage and the other, the students' long-term use. What I named "bravado" in the earlier study (Watson, 1998) may suggest a common teen characteristic. But what we might add to the interpretation is the evidence that these particular students are regular users who feel comfortable and knowledgeable in their use of the Internet mail services and Web sites for their personal use. Thus, in the personal realm, for both communicating and information-gathering and exchanging, these students' self-perceptions show both confidence and competence.

\section{School Use: "[Web authors] are citing their [sic] selves pretty much." (Jason).}

The students do not show the same kind of confidence in using the Web for school research. Polly revealed that "it's not my first choice for information, when I want information, unless there's no other way to get it." She suggests that Web sources may conflict, "even with itself or some things that you know yourself that are just not true." For her research on the artist Giotto, Polly found sites that had "dates that were off by ten years for different things. . like his different works." She trusts the authority of print publishing, by adding that books have "the editor and people like that to go through them." Jason agrees by suggesting that "people just mess around on it (the Web) so much that they're citing their (sic) selves pretty much." Mike adds that "you have to take what you know and apply it to what you read. . .because of the sites that will just be hair-brained or off the wall."

From their assessment, the students claim some frustrations around locating and trusting "official" information required for their school assignments. Polly suggests that "not knowing what's useable" suggests frustration from wanting to learn about the topic as a novice. With little background to assess the veracity of the site information, when one finds dates conflicting or 
other small errors, one is wary of trusting the site as a whole. And Mike knowingly alludes to the fact that one must know about the topic in order to measure or evaluate trustworthiness. Tara adds to the same concern,

sometimes I use the Internet to find information, but only when I have exhausted other alternatives, like the phone book or the encyclopedia. Generally the Internet is not a good place to find information -- it's way too disorganized, and it's more self-aggrandizing junk out there than anything else. However, if you have the patience to wade through the garbage, you can find useful things ... academically, the plain old Internet is pretty useless. Few Websites are concerned with presenting unbiased information. Online magazine archives that people like J. (her step-mother and also a librarian) have access to are useful, but I don't know how to use them. That's probably my fault, though.

Comments about disorganization, about bias do not appear in these students' reflections on their personal use. Willing to accept or reject their peers' or fellow hobbyists' insights into familiar topics, these users perceive that assessment is not easy with new subject matter. How does one gauge information on Websites? Jason and Mike seek "official" markers to find the best electronic sources. Jason suggests, that if a site says, "Fred's Web site or something, well, you know that that's probably not going to be real."

Understanding that online magazine and document archives exist, Tara admits that she doesn't know how to use them and assumes some responsibility for that lack of knowledge. In effect, none of the four students interviewed suggested any systematic training in information literacy. Mike said to learn the directions for Website use, "Ironically all you have to do is read the paper. They'll present it right in front of you after you do a search; it will say. . . it's got to be very specific but very accurate as well."

The level of self-direction and training varies amongst individuals. A self-proclaimed "directions reader" (Jason) with hands-on experience may begin to refine the skills of electronic searching, but what kinds of formal introduction to information literacy have these four students received?

School Use: "I don't remember any classes about using the Web." (Polly).

Mike suggests, "the one formal class I ever took which was a required class . . . was a keyboarding class." He further explains, "there are Internet classes that you can take as an elective but, in order to take that, you know, you can't take your required, your 'meat' classes. Not many people do that that I know of." College-bound students, such as Mike, find it difficult to schedule the elective technology classes. And so, one wonders how classroom teachers might infuse teaching information literacy throughout their 'meat' classes?

In a recent essay, Cuban (1999) addresses the question, "Why is greater access not translating into better classroom use?" He suggests that seven of ten American teachers, "Have computers at home and use them to prepare lessons, communicate with colleagues and friends, search the Internet, and conduct personal business. . . (using) computers at home more than at school. No technophobes here" (p. 68). However, in examining day to day working conditions and expectations for school success, he finds that teachers encounter such "contradictory advice from 
experts" (Cuban, 1999, p. 68) and "inherent unreliability of technology" (ibid., p. 47) as well as other challenges, that fewer than two out of ten "are serious users of computers and other information technologies in their classrooms" (ibid., p. 68). Meghagbhab (1997) found the same in her Georgia study. Thus, one might suggest that the teachers' use mirrors the students' model of personal use. Public school policy makers may begin to understand that it is not enough to supply schools with hardware and software without re-structuring fundamental curriculum expectations and offering staff support.

\section{Conclusion}

In listening to a small sample of high school students who have been exposed to classroom computers since their fifth grade, we find that they express greater self-confidence and competence -- expertise -- in using the Internet for their personal use than for their school use. Bilal (in progress) has found similar response 8th graders' searching both self-selected and teacher-assigned topics. Sternberg's (1998) work on developing expertise suggests that, although rates of learning differ in individuals, the amount of direct instruction, the amount of problem solving, the amount of time and effort spent in thinking about problems in the area influence levels of competence, and resulting users' confidence. Direct instruction and practice in solving the problems of seeking and evaluating information may strengthen research skills for school assignments.

How can we initiate ways to offer direct instruction for solving research problems? More than simply suggesting schools add to a school media specialist's workload, we might consider individual teachers and librarians collaborating in teaching information literacy. Learning from students' informal and personal use of the Internet, we might inspire school research through individual interests. In appreciating that exploring and assessing information --both print and electronic -- requires "problem solving" and "practice time" (Sternberg, 1998), we may gain new understanding of how to create the conditions for engaging in research projects within a school program.

School reform, curriculum and professional role changes assume commitment, hard work and time. But, if we believe that the Internet offers valuable resources to students, educators must seize ways to assist all students to learn the new tools and ways of thinking about such tools. In considering how to expand students' competence with the "children's machine" (Papert, 1986), we may not create generalized or prescribed solutions. But the first step may call for listening to the students, teachers and librarians within a single school. In such a learning situation, we assume a reflective mode of learning from the known (when do students and teachers feel confident and competent?) in order to gain insight for the unknown (how may we expand levels of confidence and competence in research skills?). Over time, we may begin to gather information from individuals to create ways of furthering the relationship between user and electronic technologies. 


\section{References}

Bilal, D. (in progress). Children's use of the Yahooligans! Web search engine, III: A comparison and a mapping methodology of cognitive behavior on different types of search tasks.

Bruner, J. (1973). Beyond the information given: Studies in the psychology of knowing. New York: Norton.

Cuban, L. (1999). The technology puzzle: Why is greater access not translating into better classroom use? Education Week, August 4, pp. 68, 47.

Dervin, B. \& Nilan, M. (1986). Information needs and uses. Annual Review of Information Science and Technology, 21, 3-33.

Dervin, B. (1977). Useful theory for librarianship. Communication, not information. Drexel Library Quarterly, 13 (3), 16-32.

Erikson, E. (1950). Childhood and society. New York: W.W. Norton and Company.

Gadamer, H. (1975). Truth and method (G. Barden \& J. Cumming, Eds. and Trans.), New York: The Seabury Press.

Kuhlthau, C. (1993). A principle of uncertainty for information seeking. The Journal of Documentation, 49, 339-355.

Lefrancois, G. (1999). The lifespan, (6th ed.). Belmont, CA: Wadsworth Publishing Co.

Meeks, J. (1990). The fragile alliance (4th ed.). Malabar, FLA: Robert E. Krieger Publishing Company.

Meghabghab, D. \& Price, C. (1997, July). The impact of a technology-rich environment. Proceedings of the International Association of School Librarianship, pp. 137-141.

Papert, S. (1993). The children's machine: Rethinking school in the age of the computer. New York: Basic Books.

Pollio, H., Henley, T. \& Thompson, C. (1997). The Phenomenology of everyday life. New York: Cambridge University Press.

Sternberg (1998). Abilities are forms of developing expertise. Educational Researcher, 27 (3), $11-20$.

Vartanian, L.R., \& Powlishta, K.K. (1996). A longitudinal examination of the social-cognitive foundations of adolescent egocentrism. Journal of Early Adolescence, 16,157-178. 
Watson, J. S. (1998). "If you don't have it, you can't find it:" A close look at students' perceptions of using technology. Journal of the American Society for Information Science, 49, 1024-1036. 